\title{
Advances in Transfemoral Amputee Rehabilitation: Early Experience with Targeted Muscle Reinnervation
}

\author{
Jason M. Souza $\cdot$ Nicholas P. Fey $\cdot$ Jennifer E. Cheesborough $\cdot$ \\ Sonya P. Agnew $\cdot$ Levi J. Hargrove $\cdot$ Gregory A. Dumanian
}

Published online: 27 March 2014

(C) Springer Science + Business Media New York 2014

\begin{abstract}
While myoelectric prosthetic devices have been used for decades in the upper extremities, only recently have motorized knee and ankle components proven durable and effective enough for use in the lower extremity amputee. The control schemes developed to capitalize on these prosthetic advances must take into account the biomechanical differences between upper and lower extremity function. Already a valuable adjunct for the myoelectric control of upper extremity prostheses, targeted muscle reinnervation in the transfemoral amputee offers the
\end{abstract}

This article is part of the Topical Collection on Trauma-Related Prosthetic Surgery.

J. M. Souza ( $\square)$. J. E. Cheesborough .

S. P. Agnew - G. A. Dumanian

Division of Plastic and Reconstructive Surgery, Northwestern University Feinberg School of Medicine, 675 N. St. Clair, Suite 19-250, Chicago, IL 60610, USA

e-mail: jasonmsouza@gmail.com

J. E. Cheesborough

e-mail: jenniecheesborough@gmail.com

S. P. Agnew

e-mail: paisles@gmail.com

G. A. Dumanian

e-mail: gdumania@nmh.org

N. P. Fey · L. J. Hargrove

Center for Bionic Medicine, Rehabilitation Institute of Chicago, 345 E. Superior St., Suite 1309, Chicago, IL, USA

e-mail: nfey@ ricres.org

L. J. Hargrove

e-mail: 1-hargrove@northwestern.edu

N. P. Fey · L. J. Hargrove

Department of Physical Medicine and Rehabilitation,

Northwestern University Feinberg School of Medicine, 345 E.

Superior St., Suite 1309, Chicago, IL 60611, USA potential to further enhance lower extremity prosthesis control and may simultaneously address post-amputation neuroma pain. Current strategies for lower extremity prosthesis control are discussed, along with a review of the transfemoral TMR technique and early clinical experience.

Keywords Targeted muscle reinnervation - Transfemoral amputee rehabilitation - Transfemoral - Lower extremity prosthesis control $\cdot$ Myoelectric device $\cdot$ Pattern recognition $\cdot$ Neuroma

\section{Introduction}

There are $\sim 1.7$ million people in the United States living with limb loss. This correlates to roughly 1 in 200 Americans, with the number of amputees in the United States projected to double by $2050[1,2]$. According to the World Health Organization, chronic disease accounts for $65 \%$ of all amputations in the United States, while trauma and cancer cause the remainder [3]. Between 2001 and 2010, the US military interventions in Iraq and Afghanistan produced 1,222 major limb amputations [4]. While the relative number of amputations due to these conflicts is small, the dramatic nature of these high-level, multiple limb combat injuries has brought amputee care to the forefront of the American consciousness. The increased public awareness of the challenges faced by amputees has been matched by a renewed scientific interest in a field of surgery that is as old as war itself.

Targeted muscle reinnervation (TMR) is one of the notable recent advances in amputee care. A true multidisciplinary endeavor, TMR combines peripheral nerve surgery with electromyography-based prosthetic control algorithms and advanced prosthetics to provide intuitive 
and coordinated control of multi-jointed prosthetic devices. Developed for use in the upper extremity amputee, TMR reroutes the distally transected brachial nerves and coapts them to small recipient nerves innervating residual limb muscles that have been left otherwise nonfunctional due to the amputation. Once reinnervated by the donor nerves, the muscles act as biologic amplifiers, creating an electromyographic (EMG) representation of the lost limb that can be captured by surface electrodes and used for prosthesis control [5-7]. The retained neural information provides a rich source of data, which when combined with pattern recognition algorithms, has been demonstrated to provide functional benefits during reaching or grasping tasks [810]. Beyond its role in improving prosthetic function, animal studies and retrospective clinical series suggest that TMR may also be effective as a strategy to treat postamputation neuroma pain [11-13, 14••]. First performed in 2002 as an experimental procedure for a patient with bilateral shoulder disarticulations, TMR has now become an established part of upper extremity amputee care [15].

Lower extremity amputations are not only more common, but are often more proximal than those that occur in the upper extremity $[2,16]$. However, the infrequent use of lower extremity myoelectric devices precluded early adaptation of the TMR technique for use in the lower extremity. Continued advances in motorized knees and ankles now justify more thorough evaluation of the possible benefits of TMR for the lower extremity amputee. Analogous to the concept behind TMR in the upper extremity, the goal of the transfemoral TMR procedure is to use nerve transfers between distally transected nerves and functionally redundant muscles in the residual limb to increase the number of independently innervated muscles from which to harvest EMG data. Early experience with this technique is promising.

\section{Lower Extremity Prosthesis Control: Previous Limitations}

Using conventional prostheses and rehabilitative care practices, individuals with lower extremity amputations commonly develop asymmetrical gait characteristics [17, 18] that increase the metabolic energy costs of transport [19]. These abnormal gait patterns are frequently associated with chronic leg and back pain, and increased incidences of degenerative joint disorders such as osteoarthritis are well-documented [20-24]. These behaviors are typically more severe and more prevalent as the level of leg amputation increases [19, 20]. This trend is to be expected, as higher levels of amputation result in greater functional loss, thus placing increased demand on the prosthetic replacement. Therefore, improved prostheses design and control methods are of particular value to the transfemoral amputee.

Nearly all commercially available prosthetic knees and ankles are mechanically passive (e.g., spring-like) devices, which do not actively deliver power about their joints. In fact, as opposed to delivering increased energy, passive devices dissipate energy from step to step. This is particularly problematic during the demanding tasks of daily living, such as ambulating up stairs or an incline, or rising from a seated position. This constraint also limits some low-demand activities, such as repositioning the prosthesis during non-weight-bearing tasks. Simple tasks like dressing or transitioning into or out of a vehicle can be difficult and require compensatory movements of the sound limbs. The development of mechanically active (i.e., powered) knee or ankle prostheses offer the ability to deliver net positive energy for user assistance during these ambulatory and non-ambulatory tasks of daily living [25-32]. However, the current control systems for these devices are lacking, particularly in transfemoral prostheses. Most devices are not intuitive, often requiring button presses or a
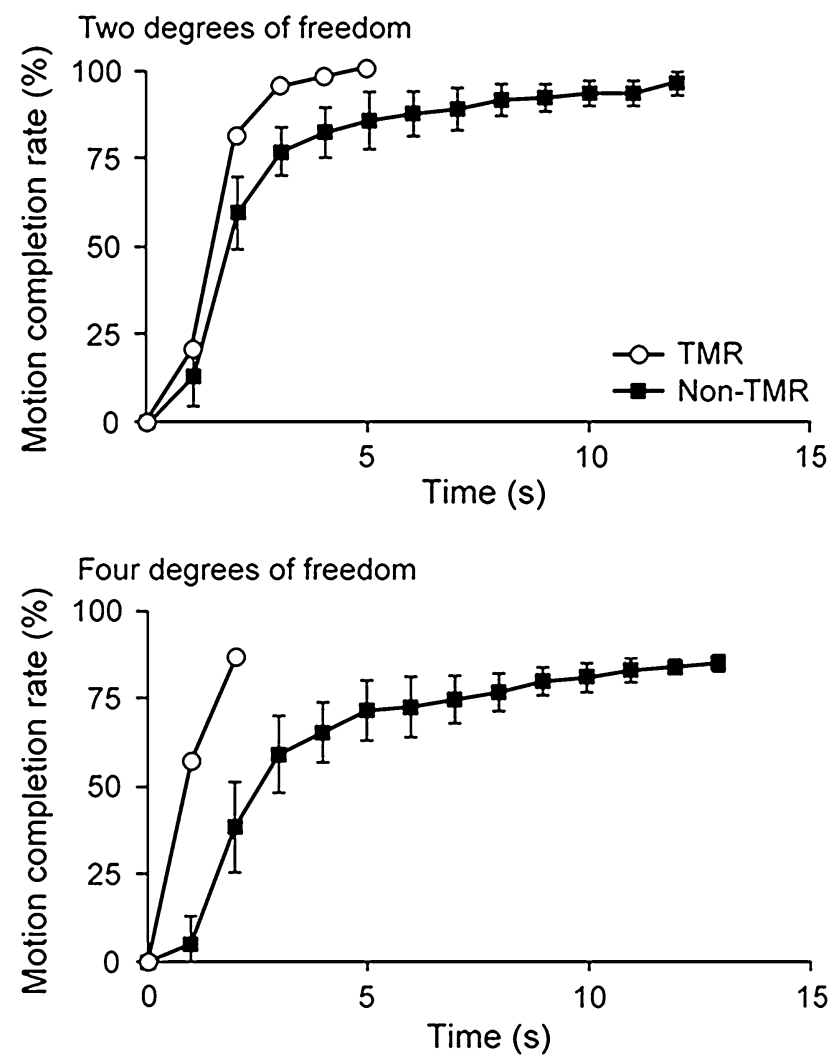

Fig. 1 Comparison of the seated (non-weight-bearing) control performance of a knee disarticulation amputee with TMR to transfemoral amputees without TMR. A pattern recognition algorithm was used to interpret surface electromyography signals acquired from natively innervated and reinnervated muscles of the residual limb. Two and four knee and ankle degrees-of-freedom tasks, respectively, were tested to examine the influence of varied task complexities. Data are from $\left[41^{\bullet \bullet}, 43^{\bullet \bullet}\right]$ 


\section{A Anterior Compartment}

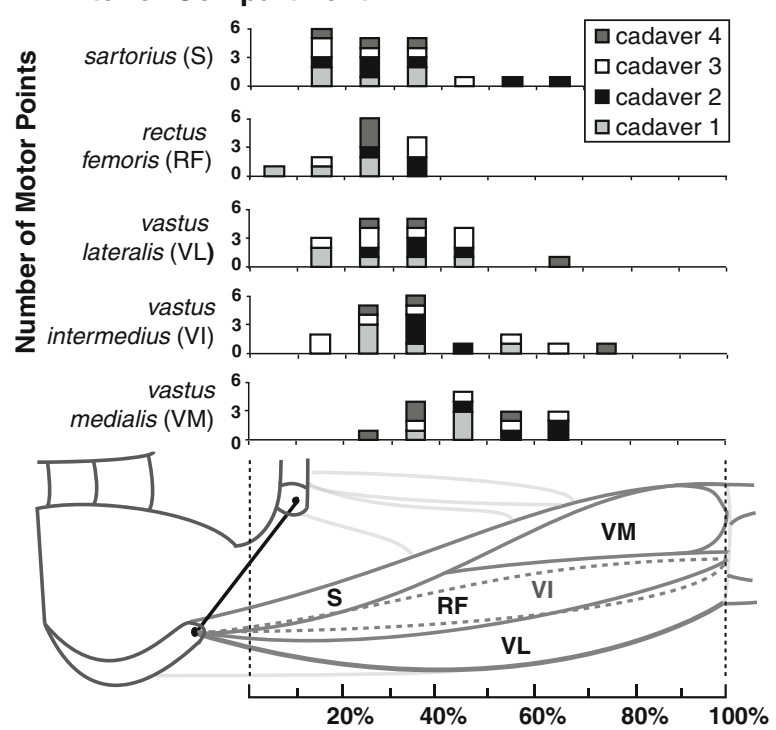

B Medial Compartment

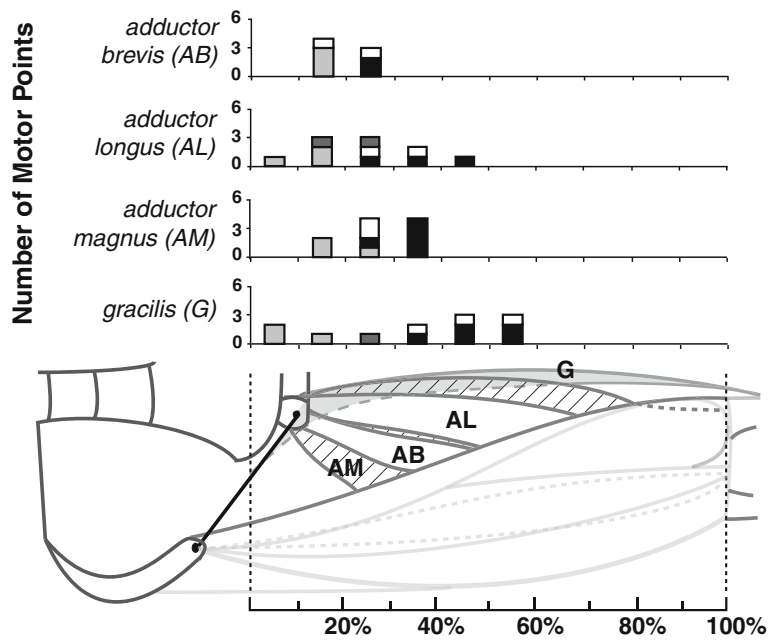

C Posterior Compartment

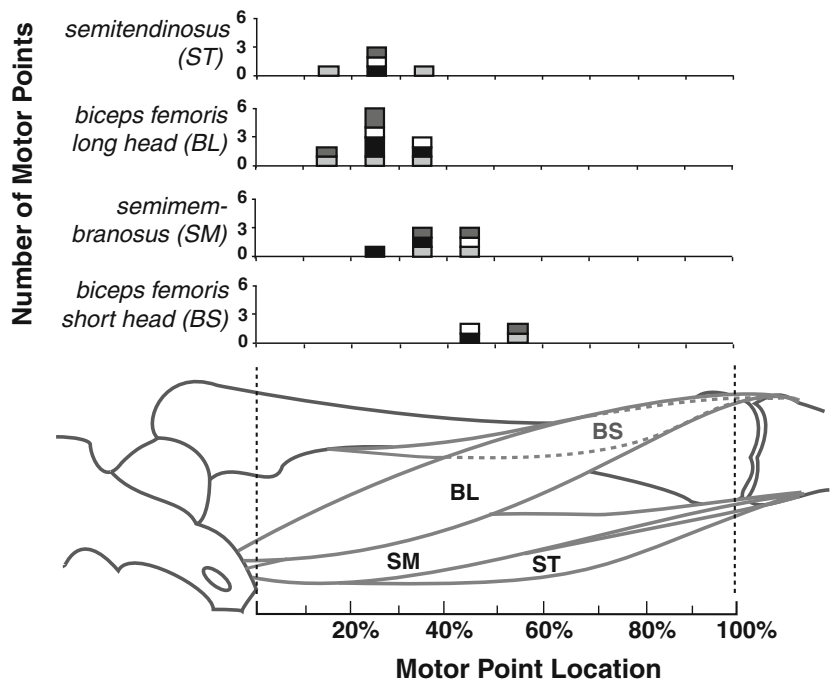

4Fig. 2 Motor point locations represented as a percentage of thigh length within the anterior, medial, and posterior compartments of the thigh. Reproduced with permission from: Agnew et al. Targeted reinnervation in the transfemoral amputee: A preliminary study of surgical technique. (Reprinted from Agnew et al. [66••]; copyright 2012, Lippincott Williams and Wilkins; with permission.)

compensatory movement to trigger a change in a device's mode of operation.

Incorporating the use of neural information into the control of powered knee and ankle prostheses allows user intent to be paired with function. Specifically, neural information can enable direct control of non-weight-bearing (i.e., non-ambulatory) movements. In addition, it can provide more seamless (without stopping), automatic (without manual adjustments), and natural (without compensation) transitions between modes of ambulation. As demonstrated in upper extremity amputees, TMR provides a means by which to deliver neural information for the control of joints distal to the level of amputation $[6,7,33]$.

\section{Lower Extremity Prosthesis Control: TMR and Other Recent Advances}

The characteristics of measured EMG signals vary with specific tasks. For example, during sustained contractions like those used during grasping, the EMG signals are typically stationary (i.e., not time varying) until the onset of muscle fatigue. Techniques for upper-limb prostheses control and exploit these signal characteristics [33-36]. Similar EMG characteristics can be observed in sustained contractions of lower-limb muscles during non-weightbearing tasks. Thus, it would follow that the pattern recognition approaches used to govern non-weight-bearing tasks of lower-limb amputees should be very similar to those used to control upper-limb functions. These approaches have been applied to transfemoral prostheses control, and high classification accuracies have been shown in offline analyses, particularly for seated knee flexion and extension movements [37, 38]. In addition, advanced filtering methods and other pattern recognition algorithms that record from smaller sets of muscle sites have shown promise when used for knee control in offline analyses or in virtual environments $[39,40]$.

A recent report combined the use of similar pattern recognition algorithms with recording EMGs from nine residual limb muscle sites in several transfemoral amputees who had not undergone TMR. This control approach was used to control both knee and ankle motions in a virtual environment $[41 \bullet \cdot]$ and while wearing a powered prosthesis [42]. Surprisingly, even without having undergone TMR, the intended knee and ankle motions in these individuals 


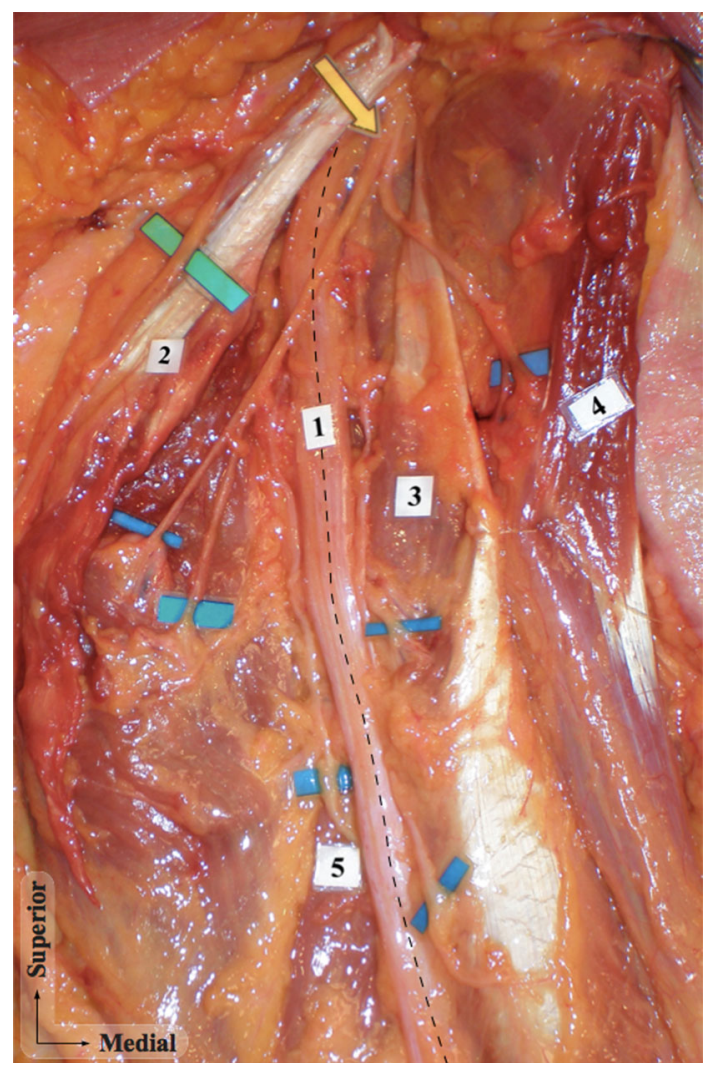

Fig. 3 Cadaveric dissection of the posterior thigh. 1 Sciatic nerve divided into tibial and common peroneal components; 2 biceps femoris long head; 3 semimembranosus; 4 ST reflected medially; 5 biceps femoris short head; (yellow arrow) origin of nerve branches to these semimembranosus, ST, and biceps femoris; (green marker) posterior femoral cutaneous nerve; (blue markers) various motor points to hamstring muscles. (Reprinted from Agnew et al. [66••]; copyright 2012, Lippincott Williams and Wilkins; with permission)

were accurately recognized more than $90 \%$ of the time. The ankle outcomes are especially notable, considering that the lower leg muscles responsible for ankle control had been amputated, and were thus not available for recording. One explanation for these findings is the possibility that ankle function is associated with specific, repeatable patterns of thigh muscle co-activation that were able to be deciphered by the algorithm used. A follow-up study showed even greater accuracy when a similar control scheme was applied to non-weight-bearing motions in a knee disarticulation amputee who had previously undergone TMR [43••]. Furthermore, these improvements in online performance were more pronounced when the movement complexity (i.e., degrees of freedom) increased (Fig. 1) [43••].

In contrast to the EMG patterns exhibited during nonweight-bearing functions, lower limb EMG recordings during overground ambulation show greater variability in time (i.e., are non-stationary) and are cyclic in nature. These differences necessitate alternative pattern recognition-based approaches for lower limb prosthesis control. Alternative algorithms have been developed to select EMG data from discrete portions of the gait cycle to predict various modes of ambulation (e.g., level ground walking, stair ascent/descent, and ramp ascent/descent) [44]. These approaches merge EMG data with data from mechanical sensors (e.g., acceleration, load, or position data) within the prostheses to anticipate transitions between various ambulation modes. This fusion of signal modalities (EMG and mechanical) has shown better performance than using mechanical sensor data alone [44].

A more advanced approach to lower extremity prosthesis control incorporates time-history information (how EMG and mechanical signals vary in time) collected over the course of the gait cycle to allow ambulation mode switching decisions to occur at specific gait cycle events (i.e., either at toe-off or heel-strike). This control scheme has been tested on multiple transfemoral amputees without TMR. These studies found that combining time-history information with a fusion of mechanical and EMG data offers the lowest error rate when predicting ambulation mode $[45,46]$. This advanced pattern recognition approach was evaluated across various ambulation modes in the same knee-disarticulation-level TMR patient previously mentioned. While the error rate for ambulation mode prediction was low using mechanical data and EMG data captured exclusively from natively innervated muscles $(2.2 \%)$, this error rate was even lower $(1.8 \%)$ when EMG data from the reinnervated muscles were added [43••].

The additional neural information provided by TMR may provide additional benefits. For example, the supplemental lower leg information provided by TMR may allow for improvement of the device's within-mode performance during ambulation, thus providing a greater degree of useradaptability. Recent research has used EMG from the residual limb gastrocnemius muscle of transtibial amputees to modify the plantar-flexion mechanics of a powered ankle prosthesis during the terminal stance phase of walking [47]. There is potential that transfemoral amputees with TMR could provide similarly beneficial control information to modify the late stance performance of a prosthetic knee and/or ankle in an analogous manner. This would be impossible in transfemoral amputees without TMR.

\section{TMR as a Strategy for Post-Amputation Neuroma Treatment}

Despite being developed primarily for prosthesis function, TMR has been demonstrated to have a beneficial effect on residual limb neuroma pain. This finding is particularly encouraging in light of the fact that at least $25 \%$ of all major limb amputees, and upwards of $71 \%$ of those with 
traumatic amputations, will develop chronic localized pain due to symptomatic end neuromas [48-51]. These painful neuromas often limit prosthesis use, thus further reducing the functional capacity of the amputee.

Early clinical observations of improved residual limb pain following TMR were confirmed by a retrospective review of 28 consecutive upper extremity TMR cases performed at our institution, in conjunction with the San Antonio Military Medical Center. Despite the fact that $58 \%$ of patients presented with symptomatic residual limb neuromas, $93 \%$ experienced complete resolution of neuroma pain and $100 \%$ were successfully fit with a prosthesis [14••]. A separate review of 31 TMR cases performed at the University of Washington's Harborview Medical Center found the technique to be similarly effective for the management of residual neuroma pain [14••].

In addition to these clinical reviews, a novel rabbit neuroma model demonstrated significant improvement in fascicle number and size following neuroma excision and subsequent TMR [12]. Similarly, a rat hind-limb model showed improved nerve histology after TMR was performed with both mixed and pure sensory nerves. Most notably, TMR significantly decreased histologic evidence of neuroma formation when compared to burying of the nerve ends into natively innervated muscles-a technique many consider to be the gold standard treatment for end neuromas $[14 \cdot \bullet]$. These preclinical findings are consistent with a clinical report showing nerve repair to be superior to neuroma excision and muscle/bone implantation for the treatment of symptomatic neuromas in the intact upper extremity [52]. By providing both a distal target and a vascularized scaffold upon which to guide sprouting nerve axons, TMR offers the potential to restore continuity to the peripheral nervous system despite amputation of the native distal nerve segments. Motivated by these retrospective outcomes and supportive preclinical findings, seven cases of lower extremity TMR have been performed at our institution for the primary purpose of improving persistent post-amputation neuroma pain. Standardized patientreported pain outcomes were collected prior to these procedures. However, while our early experience has been uniformly positive, the duration of follow-up is still too short to allow for meaningful interpretation of the pain outcomes data. Beyond this small subset of patients, a large multi-institutional randomized clinical trial of TMR versus standard neuroma excision and muscle implantation is now underway.

\section{Cadaveric Studies}

In order to apply the technique of targeted reinnervation to transfemoral amputees, a thorough understanding of the relative location of motor points in the lower extremity is required. To date, most literature on the neuroanatomy of the thigh and leg have focused on limited groups of muscles, with the purpose of studying orthopaedic exposures, or providing landmarks for percutaneous nerve blocks [53$65]$. We recently studied fresh cadavers to determine the locations of motor points in the lower limb as well as the technical feasibility of performing targeted reinnervation on transfemoral amputees [66••]. The location of motor points was expressed as a percentage of cadaver thigh length, using easily palpable surgical landmarks (anterior superior iliac spine, pubic tubercle, ischial tuberosity, patella, medial malleolus) in order to allow application of the map to all patients regardless of thigh length. The relative location and number of motor points for the anterior, medial, and posterior compartments of the thigh are illustrated in Fig. 2. In both the anterior and medial compartments, the highest density of motor points was clustered in the proximal half of the thigh. In the posterior compartment, the motor points of the long head of the biceps femoris (BFL) and the semitendinosus (ST) were concentrated proximally, whereas the motor points of the semimembranosus and short head of the BFL were mostly located around the midpoint of the thigh. Interestingly, the motor branches to the hamstring muscles were consistently noted to be very distinct and medial to the sciatic nerve (Fig. 3). In all cadavers, the tibial and common peroneal divisions of the sciatic nerve were easily visualized as separate entities through the epineurium of the sciatic nerve along the entire length of the posterior thigh.

\section{Current Surgical Technique}

After the initiation of general anesthesia without muscle relaxant, the patient is positioned prone on the operating room table. To assist with localization of the target motor end points, the relative length of the residual limb is determined based on a comparison to the intact contralateral limb. A mark is made halfway between the ischial tuberosity and the popliteal crease of the intact leg, representing $50 \%$ of the upper leg length. Using this mark as a guide, a corresponding mark is made on the involved residual limb (Fig. 4a). This mark serves as a reference point for identification of the recipient motor nerve branches, which, as described above, are typically found at a level between 20 and $40 \%$ of the upper leg length. Next, the raphe between the long head of the BFL and ST is then palpated and marked with a longitudinal line extending proximally from the previously marked $50 \%$ point. The residual limb is then circumferentially prepared, and a $10-12 \mathrm{~cm}$ longitudinal incision is made along the previously marked raphe. The interspace between the BFL and 


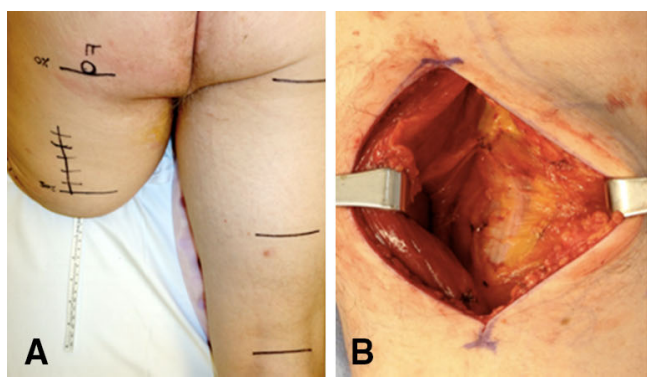

Fig. 4 Transfemoral amputee with sciatic neuroma requiring operative treatment. The patient expressed interest in pursuing improved myoelectric prosthetic control. a Coronal MRI demonstrating a sciatic nerve end neuroma. b Preoperative markings demonstrating the use of the intact limb for reference. c Dissection of the sciatic nerve into its

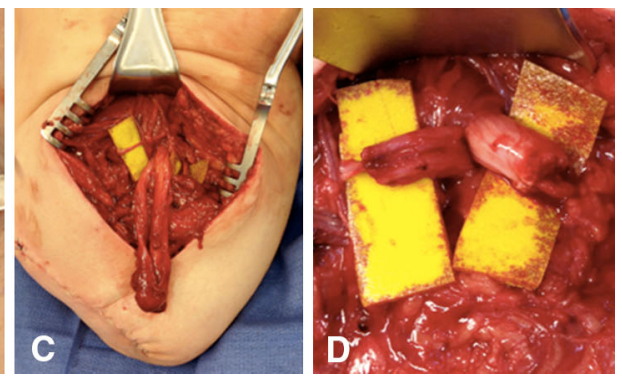

components prior to nerve transfer. Recipient motor nerve branches to the biceps femoris and semitendinosus have been identified (yellow backgrounds). d Nerve coaptations: common peroneal nerve component to biceps femoris, tibial nerve component to semitendinosus
Fig. 5 High-density electromyography imaging experiment from a patient who received TMR at our institution. The patient was able to readily control a virtual prosthesis (knee and ankle) in real-time by generating strong EMG patterns for each motion from his natively innervated and reinnervated muscles $[67 \bullet \bullet]$

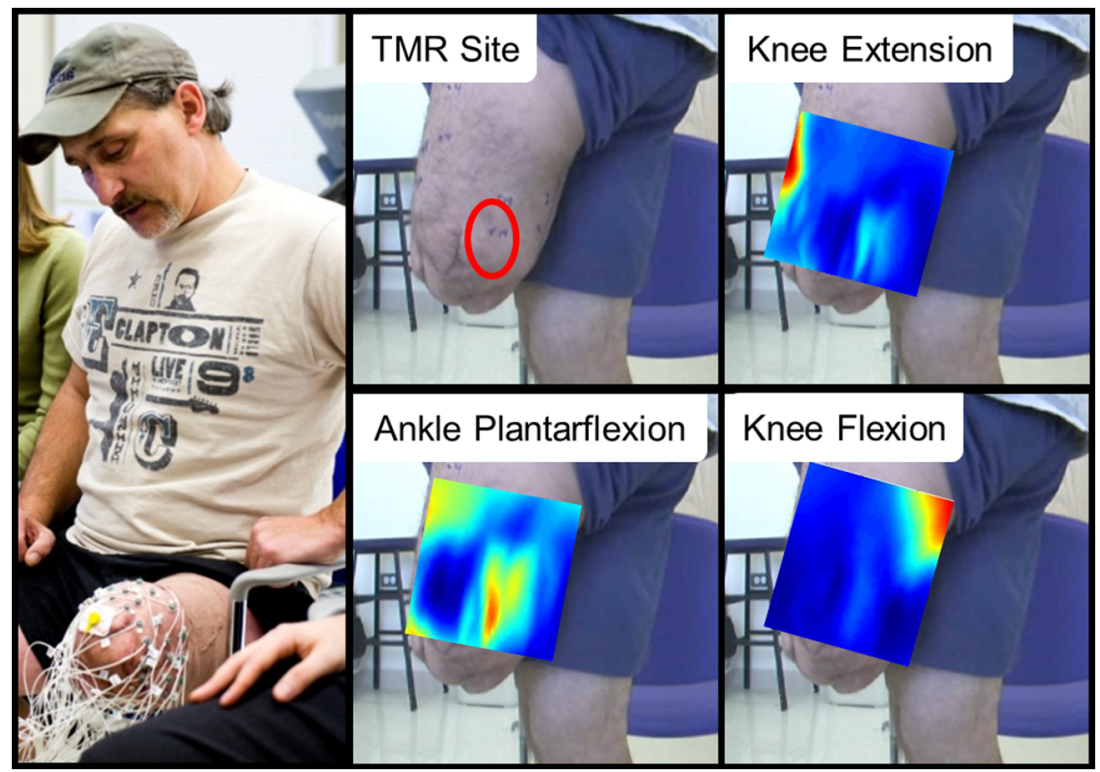

ST is then bluntly developed, yielding visualization of the sciatic nerve within the fat pad deep to these muscles (Fig. 4b). If the sciatic nerve is not immediately visible, it can be easily located with a palpation of the fat pad. Once the nerve has been dissected free of the surrounding fat, a division between the tibial nerve (TN) and common peroneal nerve (CPN) components of the sciatic nerve is visible through the overlying epineurium. The epineurium is incised and the two components are then separated (Fig. 4c). In most cases, the two components are amenable to separation via blunt dissection. If necessary, limited sharp dissection can be used to facilitate further proximal dissection. The extent of the proximal dissection is dictated by the location of the target motor nerve branches. Thus, attention is turned to identification of the motor nerve branches to the BFL and ST within the proximal portion of the previously developed interspace. The target motor nerve branches are found entering the deep surface of these muscles. A standard nerve stimulator is used to assist with identification of the recipient nerve branches and to confirm innervation of the intended target muscles. The sciatic nerve is then transected distally. No specific attempt is made to remove the distal neuroma segment in its entirety. The CPN and TN components are then mobilized proximally as needed to facilitate tension-free coaptation to their corresponding motor nerve recipients. Typically, the CPN component is coapted to the BFL motor nerve branch, while the TN component is coapted to the ST motor nerve branch (Fig. 4d). Following the nerve coaptations, the posterior leg incision is closed in layers. While a proximally-based adipofascial flap can be used to enhance separation of the BFL and ST muscles, advances in EMG pattern recognition have made spatial differentiation of the reinnervated muscle signals less critical. Following closure, the residual limb is dressed in a compression bandage, with closed suction drainage used as needed based on the 
degree of muscular dissection. Prosthetic usage is avoided for 1 month postoperatively, though early shrinker or liner wear is encouraged.

\section{Clinical Experience}

At our institution, three patients have undergone the transfemoral TMR procedure according to the technique described. Two cases were performed as part of secondary revisions for sciatic nerve neuroma pain, while the remaining case was performed immediately following an oncologic amputation for osteosarcoma of the distal femur. All patients tolerated the procedure well, with no postoperative complications at a mean follow-up of 8.5 months. Long-term data and prosthetic control outcomes for all patients are not yet available. However, preliminary control outcomes evaluated in one subject are encouraging [67••]. Strong EMG patterns from native and reinnervated muscle sites for intended knee and ankle movements were found (Fig. 5), and the patient could readily control a virtual prosthesis in real-time [67••]. In addition to the three cases performed at our institution, our colleagues at the University of Washington have reported an additional case of TMR in a patient with a knee disarticulation. The prosthetic control outcomes from this case are encouraging, and have been highlighted in a recent report in the New England Journal of Medicine [43••].

\section{Conclusions}

The evolution in motorized knee and ankle components of lower extremity prostheses has introduced a need for more advanced approaches to prosthesis control. Some of the myoelectric control schemes useful in the upper extremity can be applied to the lower extremity, but must be merged with mechanical and timing-based control methods if seamless and natural ambulation is to be achieved. TMR in the transfemoral amputee offers the potential to further enhance prosthesis control by providing an EMG representation of the amputated lower leg muscles within the residual limb. While the early results are promising, critical assessment of outcomes will be needed in order to obtain a deeper understanding of the true benefits offered by this technique.

\section{Compliance with Ethics Guidelines}

Conflict of interest Levi J. Hargrove has received grant support from the Department of Defense. Jason M. Souza, Nicholas P. Fey, Jennifer E. Cheesborough, Sonya P. Agnew, and Gregory A. Dumanian declare that they have no conflicts of interest.

Human and Animal Rights and Informed Consent With regard to the authors' research cited in this paper, all institutional and national guidelines for the care and use of laboratory animals were followed, and all procedures were followed in accordance with the ethical standards of the responsible committee on human experimentation and with the Helsinki Declaration of 1975, as revised in 2000 and 2008 .

\section{References}

Papers of particular interest, published recently, have been highlighted as:

- Of importance

•• Of major importance

1. Adams PF, Hendershot GE, Marano MA. Current estimates from the National Health Interview Survey, 1996. Vital Health Stat 10. 1999;(200):1-203.

2. Ziegler-Graham K, MacKenzie EJ, Ephraim PL, Travison TG, Brookmeyer R. Estimating the prevalence of limb loss in the United States: 2005 to 2050. Arch Phys Med Rehabil. 2008;89(3):422-9.

3. World Health Organization. United States Department of Defense MRARPMRH, USA. A manual for the rehabilitation of people with limb amputation. 2004 [updated 2004]. (http://www.posna. org/news/amputations.pdf). Accessed 19 March 2013.

4. Fischer H. US Military Casualty Statistics: Operation New Dawn, Operation Iraqi Freedom, and Operation Enduring Freedom Congressional Research Service, Report for Congress. 2010.

5. Hijjawi JB, Kuiken TA, Lipschutz RD, Miller LA, Stubblefield KA, Dumanian GA. Improved myoelectric prosthesis control accomplished using multiple nerve transfers. Plast Reconstr Surg. 2006;118:1573-8.

6. Kuiken TA, Dumanian GA, Lipschutz RD, Miller LA, Stubblefield KA. The use of targeted muscle reinnervation for improved myoelectric prosthesis control in a bilateral shoulder disarticulation amputee. Prosthet Orthot Int. 2004;28:245-53.

7. O'Shaughnessy KD, Dumanian GA, Lipschutz RD, Miller LA, Stubblefield K, Kuiken TA. Targeted reinnervation to improve prosthesis control in transhumeral amputees. A report of three cases. J Bone Joint Surg Am. 2008;90:393-400.

8. Hargrove L, Lock B, Simon A. Pattern recognition control outperforms conventional myoelectric control in upper limb patients with targeted muscle reinnervation. In: Proceedings of the 35th international conference of the IEEE Engineering in Medicine and Biology Society, Osaka, Japan. 2013.

9. Miller, L., et al. A comparison of direct control and pattern recognition control of a seven degree-of-freedom hand wrist system. In: ISPO, Hyderabad, India. 2013.

10. Miller LA, et al. Improved myoelectric prosthesis control using targeted reinnervation surgery: a case series. Neural systems and rehabilitation engineering. IEEE Trans Neural Syst Rehabil Eng. 2008;16(1):46-50.

11. Kim PS, Ko J, O'Shaughnessy KK, Kuiken TA, Dumanian GA. Novel model for end-neuroma formation in the amputated rabbit forelimb. J Brachial Plex Peripher Nerve Inj. 2010;5:6. doi:10. 1186/1749-7221-5-6.

12. Kim PS, Ko JH, O'Shaughnessy KK, Kuiken TA, Pohlmeyer EA, Dumanian GA. The effects of targeted muscle reinnervation on neuromas in a rabbit rectus abdominis flap model. J Hand Surg Am. 2012;37(8):1609-16.

13. Ko JH, Kim PS, O'Shaughnessy KD, Ding X, Kuiken TA, Dumanian GA. A quantitative evaluation of gross versus histologic 
neuroma formation in a rabbit forelimb amputation model: potential implications for the operative treatment and study of neuromas. J Brachial Plex Peripher Nerve Inj. 2011;13(6):8. doi:10.1186/1749-7221-6-8.

14. $\bullet$ Ko JH, Kim PS, Smith DG. Targeted muscle reinnervation as a strategy for neuroma prevention. In Kuiken TA, Barlow AK, Schultz AE, editors. Targeted muscle reinnervation: a neural interface for artificial limbs. Boca Raton: CRC Press; 2013. This book chapter explains the rationale behind the use of TMR for neuroma management, and provides preclinical and clinical evidence to support the use of TMR for this purpose.

15. Kuiken TA, et al. The use of targeted muscle reinnervation for improved myoelectric prosthesis control in a bilateral shoulder disarticulation amputee. Prosthet Orthot Int. 2004;28(3):245-53.

16. Dillingham TR, Pezzin LE, MacKenzie EJ. Limb amputation and limb deficiency: epidemiology and recent trends in the United States. South Med J. 2002;95(8):875-83.

17. Robinson JL, Smidt GL, Arora JS. Accelerographic, temporal, and distance gait factors in below-knee amputees. Phys Ther. 1977;57(8):898-904.

18. Winter DA, Sienko SE. Biomechanics of below-knee amputee gait. J Biomech. 1988;21(5):361-7.

19. Waters RL, et al. Energy cost of walking of amputees: the influence of level of amputation. J Bone Joint Surg Am. 1976; 58(1):42-6.

20. Gailey R, et al. Review of secondary physical conditions associated with lower-limb amputation and long-term prosthesis use. J Rehabil Res Dev. 2008;45(1):15-29.

21. Burke MJ, Roman V, Wright V. Bone and joint changes in lower limb amputees. Ann Rheum Dis. 1978;37(3):252-4.

22. Ephraim PL, et al. Phantom pain, residual limb pain, and back pain in amputees: results of a national survey. Arch Phys Med Rehabil. 2005;86(10):1910-9.

23. Kulkarni J, et al. Chronic low back pain in traumatic lower limb amputees. Clin Rehabil. 2005;19(1):81-6.

24. Smith DG, et al. Phantom limb, residual limb, and back pain after lower extremity amputations. Clin Orthop Relat Res. 1999;361: 29-38.

25. Au SK, et al. Powered ankle-foot prosthesis for the improvement of amputee ambulation. In: Annual international conference of the IEEE Engineering in Medicine and Biology Society. 2007. pp. 3020-6.

26. Au SK, Herr HM. Powered ankle-foot prosthesis-the importance of series and parallel motor elasticity. IEEE Robot Autom Mag. 2008;15(3):52-9.

27. Au SK, Weber J, Herr H. Biomechanical design of a powered ankle-foot prosthesis. In: 2007 IEEE 10th International conference on rehabilitation robotics, vol. 1 and 2. 2007. pp. 298-303.

28. Fite K, et al. Design and control of an electrically powered knee prosthesis. In: 2007 IEEE 10th International conference on rehabilitation robotics, vol. 1 and 2. 2007. pp. 902-905.

29. Sup F, Bohara A, Goldfarb M. Design and control of a powered knee and ankle prosthesis. In: Proceedings of the 2007 IEEE International conference on robotics and automation, vol. 1-10. 2007. pp. 4134-4139.

30. Sup F, Bohara A, Goldfarb M. Design and control of a powered transfemoral prosthesis. Int J Robot Res. 2008;27(2):263-73.

31. Au S, Berniker M, Herr H. Powered ankle-foot prosthesis to assist level-ground and stair-descent gaits. Neural Netw. 2008;21(4): 654-66.

32. Sup F, et al. Preliminary evaluations of a self-contained anthropomorphic transfemoral prosthesis. IEEE ASME Trans Mechatron. 2009;14(6):667-76.

33. Li G, Schultz AE, Kuiken TA. Quantifying pattern recognitionbased myoelectric control of multifunctional transradial prostheses. IEEE Trans Neural Syst Rehabil Eng. 2010;18(2):185-92.
34. Zhou P, et al. Decoding a new neural-machine interface for control of artificial limbs. J Neurophysiol. 2007;98(5):2974-82.

35. Williams TW. Control of powered upper extremity prostheses. In: Meier RH, Atkins DJ, editors. Functional restoration of adults and children with upper extremity amputation. New York: Demos Medical Publishing; 2004. p. 207-24.

36. Hudgins B, Parker P, Scott RN. A new strategy for multifunction myoelectric control. IEEE Trans Biomed Eng. 1993;40(1):82-94.

37. Hillstrom H, Moskowitz GD. Robust intent recognition for prosthesis control. In: 14th Annual international conference of the IEEE Engineering in Medicine and Biology Society 1992.

38. Myers D, Moskowitz GD. Myoelectric pattern recognition for use in the volitional control of above-knee prostheses. IEEE Trans Syst Man Cybern. 1981;11(4):296-302.

39. Delis A, et al. Myoelectric knee angle estimation algorithms for control of active transfemoral leg prostheses. In: Mwasiagi J, editor. Self organizing maps-applications and novel algorithm design. Viena: InTech; 2011.

40. Ha KH, Varol HA, Goldfarb M. Volitional control of a prosthetic knee using surface electromyography. IEEE Trans Biomed Eng. 2011;58(1):144-51.

41. • Hargrove L, et al. Real-time myoelectric control of knee and ankle motions for transfemoral amputees. JAMA. 2011;305(15): 1442-1444. Study identifying the ability of non-TMR transfemoral amputees to control a prosthetic knee and ankle using the excitations of natively innervated residual limb muscles while seated.

42. Hargrove L, et al. Non-weight-bearing neural control of a powered transfemoral prosthesis. J Neuroeng Rehabil. 2013;10(1):62.

43. • Hargrove LJ, et al. Robotic leg control with EMG decoding in an amputee with nerve transfers. N Engl J Med. 2013;369(13): 1237-1242. Experimental study demonstrating the benefits of transfemoral TMR in the control of prosthesis during ambulation and while seated.

44. Huang H, et al. Continuous locomotion-mode identification for prosthetic legs based on neuromuscular-mechanical fusion. IEEE Trans Biomed Eng. 2011;58(10):2867-75.

45. Young A, Simon A, Hargrove L. An intent recognition strategy for transfemoral amputee ambulation across different locomotion modes. In: Proceedings of the 35th international conference of the IEEE Engineering in Medicine and Biology Society, Osaka, Japan. 2013.

46. Young AJ, et al. Intent recognition in a powered lower limb prosthesis using time history information. Ann Biomed Eng, 2013. doi:10.1007/s10439-013-0909-0.

47. Wang J, Kannape O, Herr H. Proportional EMG control of ankle plantar flexion in a powered transtibial prosthesis. In IEEE International conference on rehabilitation robotics (ICORR), Seattle, USA. 2013

48. Pierce RO Jr, Kernek CB, Ambrose TA 2nd. The plight of the traumatic amputee. Orthopedics. 1993;16:793-7.

49. Ducic I, Mesbahi AN, Attinger CE, Graw K. The role of peripheral nerve surgery in the treatment of chronic pain associated with amputation stumps. Plast Reconstr Surg. 2008;121:908-14.

50. Hanley MA, Ehde DM, Jensen M, Czerniecki J, Smith DG, Robinson LR. Chronic pain associated with upper-limb loss. Am J Phys Med Rehabil. 2009;88:742-52.

51. Tintle SM, Keeling JJ, Shawen SB, Forseberg JA, Potter BK. Traumatic and trauma-related amputations. J Bone Joint Surg Am. 2010;92(2852-2868):2934-45.

52. Guse DM, Moran SL. Outcomes of the surgical treatment of peripheral neuromas of the hand and forearm: a 25 -year comparative outcome study. Ann Plast Surg. 2013;71(6):654-8.

53. Yoo WK, Chung IH, Park CI. Anatomic motor point localization for the treatment of gastrocnemius muscle spasticity. Yonsei Med J. 2002;43(5):627-30. 
54. Deltombe T, De Wispelaere J-F, Gustin T, Jamart J, Hanson P. Selective blocks of the motor nerve branches to the soleus and tibialis posterior muscles in the management of the spastic equinovarus foot. Arch Phys Med Rehabil. 2004;85(1):54-8.

55. Seidel PM, Seidel GK, Gans BM, Dijkers M. Precise localization of the motor nerve branches to the hamstring muscles: an aid to the conduct of neurolytic procedures. Arch Phys Med Rehabil. 1996;77(11):1157-60.

56. Tran D, Clemente A, Finlayson RJ. A review of approaches and techniques for lower extremity nerve blocks. Can J Anaesth. 2007;54(11):922-34.

57. Albert T, Yelnik A, Colle F, Bonan I, Lassau JP. Anatomic motor point localization for partial quadriceps block in spasticity. Arch Phys Med Rehabil. 2000;81(3):285-7.

58. Sung DH, Jung J-Y, Kim H-D, Ha BJ, Ko YJ. Motor branch of the rectus femoris: anatomic location for selective motor branch block in stiff-legged gait. Arch Phys Med Rehabil. 2003;84(7): 1028-31.

59. Crystal R, Malone AA, Eastwood DM. Motor points for neuromuscular blockade of the adductor muscle group. Clin Orthop Relat Res. 2005;437:196-200.

60. Hospodar PP, Ashman ES, Traub JA. Anatomic study of the lateral femoral cutaneous nerve with respect to the ilioinguinal surgical dissection. J Orthop Trauma. 1999;13(1):17-9.

61. Vloka JD, Hadzic A, Drobnik L, Ernest A, Reiss W, Thys DM. Anatomical landmarks for femoral nerve block: a comparison of four needle insertion sites. Anesth Analg. 1999;89(6):1467-70.
62. Dayan V, Cura L, Cubas S, Carriquiry G. Surgical anatomy of the saphenous nerve. Ann Thorac Surg. 2008;85(3):896-900.

63. Lee JH, Kim HW, Im S, et al. Localization of motor entry points and terminal intramuscular nerve endings of the musculocutaneous nerve to biceps and brachialis muscles. Surg Radiol Anat. 2010;32(3):213-20.

64. Iyer VG, Shields CB. Isolated injection injury to the posterior femoral cutaneous nerve. Neurosurgery. 1989;25(5):835-8.

65. Windhofer C, Brenner E, Moriggl B, Papp C. Relationship between the descending branch of the inferior gluteal artery and the posterior femoral cutaneous nerve applicable to flap surgery. Surg Radiol Anat. 2002;24(5):253-7.

66. •• Agnew SP, Schultz AE, Dumanian GA and Kuiken TA. Targeted reinnervation in the transfemoral amputee: A preliminary study of surgical technique. Plast Reconstr Surg 2012;129: 187-194. Cadaveric study demonstrating the technical feasibility of transfemoral TMR and identifying the location of relevant recipient motor branches in the upper leg.

67. •• Kuiken TA, Schultz Feuser AE, Barlow AK. Targeted muscle reinnervation a neural interface for artificial limbs. In: Webster $\mathrm{JG}$, et al., editor. Series in medical physics and biomedical engineering, vol. 28. CRC Press, Taylor and Francis Group: Boca Raton; 2013. Textbook presenting the multidisciplinary evolution of implementing targeted muscle reinnervation in upper extremity amputees and its more recent application in the lower extremity. 